$4^{\text {th }}$ International Meeting on Calcitonin Gene-Related Peptide (CGRP)

TheScientificWorld (2001) 1(S1), 36

ISSN 1532-2246; DOI 10.1100/tsw.2001.403

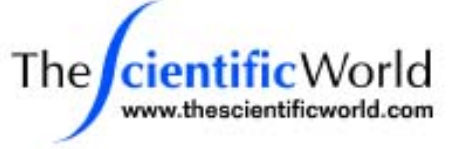

\title{
MODULATION OF THE EXPRESSION OF CALCITONIN GENE-RELATED PEPTIDE AND SUBSTANCE P IN CULTURED DORSAL ROOT GANGLIA BY OPIOID RECEPTOR AGONISTS. INVOLVEMENT OF THE PKC PATHWAY
}

\author{
S. Bélanger ${ }^{1,2}$, W. $\mathrm{Ma}^{2}$, J.-G. Chabot ${ }^{2}$, and R. Quirion ${ }^{1,2}$ \\ ${ }^{1}$ Department of Pharmacology and Therapeutics, ${ }^{2}$ Douglas Hospital Research Center and \\ Department of Psychiatry, McGill University, Verdun, QC, Canada, H4H 1R3
}

The mechanisms involved in morphine tolerance are poorly understood. It was reported that calcitonin gene-related peptide (CGRP) immunoreactivity was increased in the spinal dorsal horn during morphine tolerance and an in vitro repetitive morphine treatment was able to mimic the in vivo results by inducing increases in CGRP- and substance P (SP)-immunoreactive (IR) neurons in cultured dorsal root ganglia (DRG). The aim of this study was to establish which subtypes of opioid receptors are involved in the induction of CGRP and SP in cultured rat DRG neurons and to examine the signaling pathway involved in the induction of these neuropeptides following repetitive opiate treatments.

Following treatment with either of the three opioid agonists [ $\mu$; DAMGO, $\delta$; DPDPE, $\kappa$; $\mathrm{U} 50488 \mathrm{H}]$, the number of CGRP- and SP-IR neurons increased significantly, in a concentrationdependent manner. Double-immunofluorescence staining showed that the three opioid receptors were colocalized with both of the pain-related neuropeptides. Protein kinase C (PKC)-IR was found to be significantly increased following a repetitive treatment with DAMGO. Doubleimmunofluorescence staining showed the colocalization of PKC $\alpha$ with CGRP or SP in cultured DRG neurons. Moreover, a combined treatment of opioids with PKC inhibitors (chelerythrine chloride or GO6976) was able to block the effects of the opioid treatment on increased CGRP-like IR.

These data suggest that the three opioid receptors are expressed in DRG neurons and may be involved in the induction of CGRP and SP by opiates and that PKC probably plays a role in the signaling pathway leading to the upregulation.

Supported by grant from CIHR. 

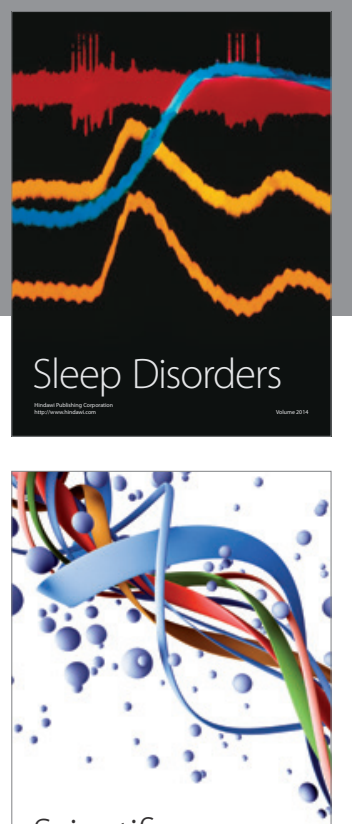

Scientifica
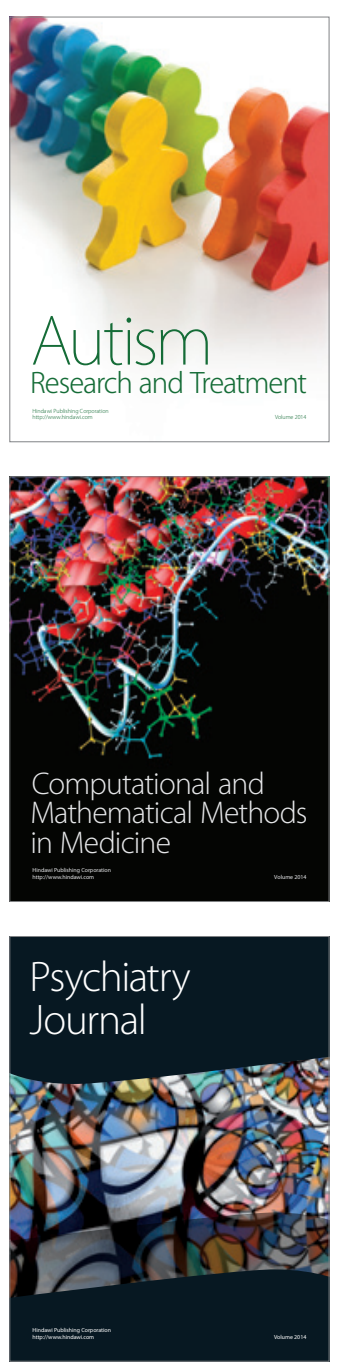
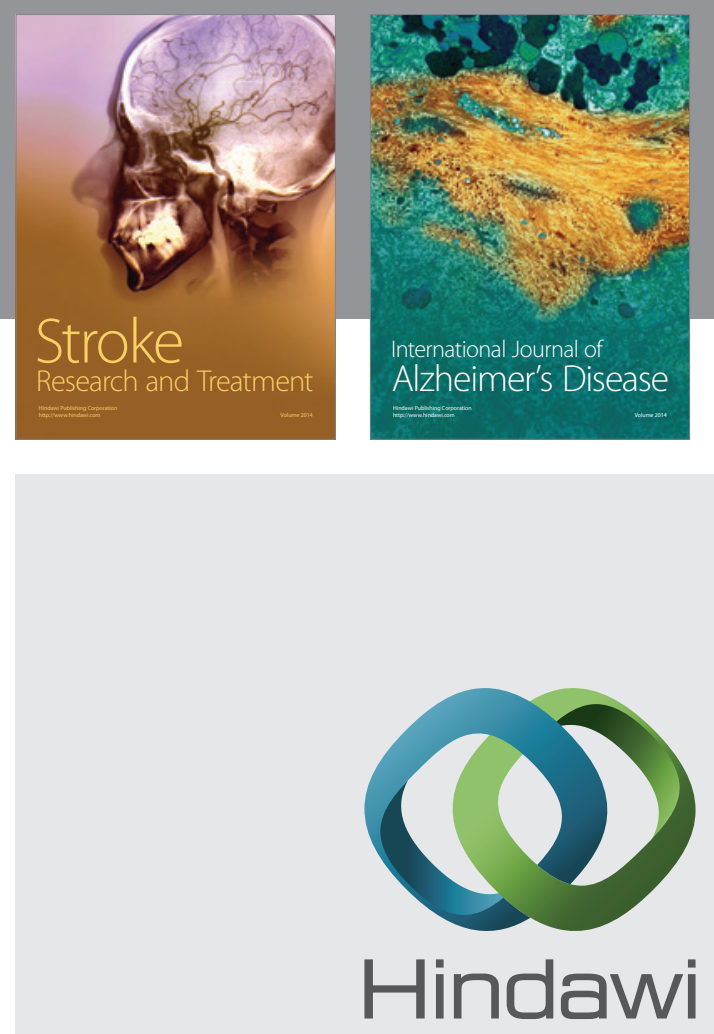

Submit your manuscripts at

http://www.hindawi.com
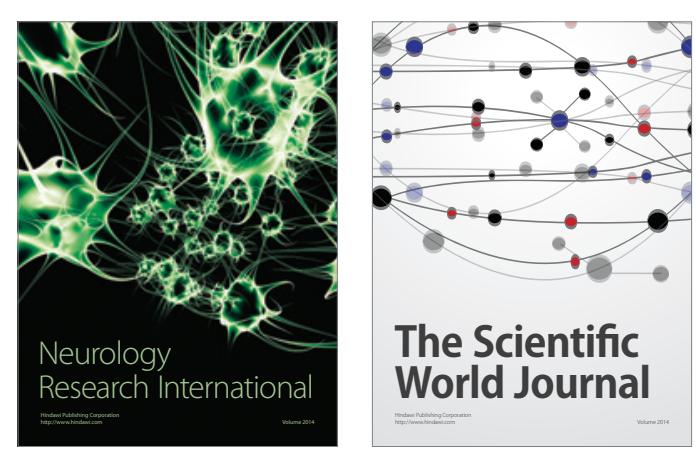

The Scientific World Journal

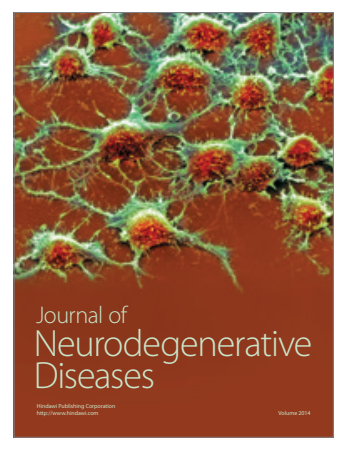

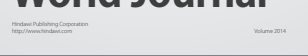

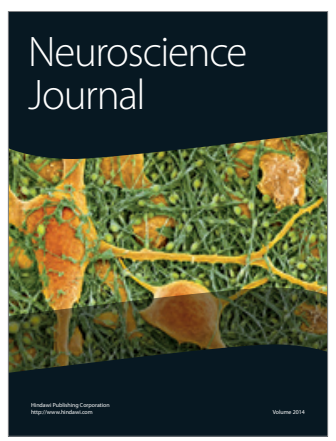

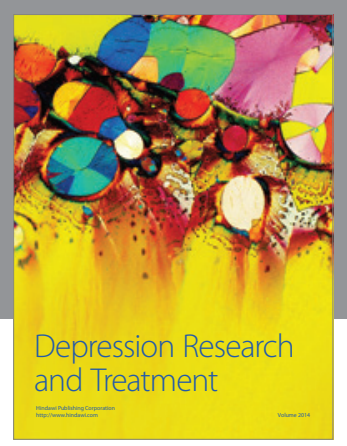
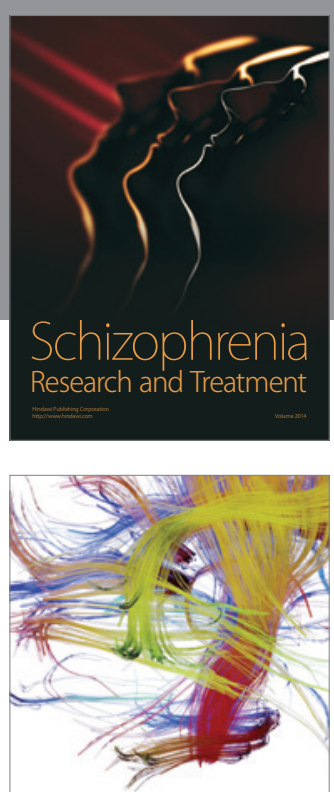

Brain Science

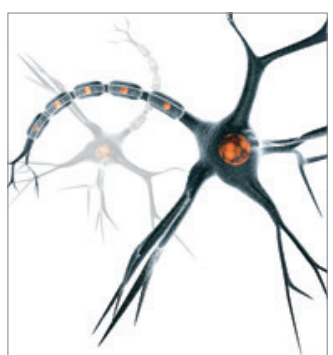

Neural Plasticity
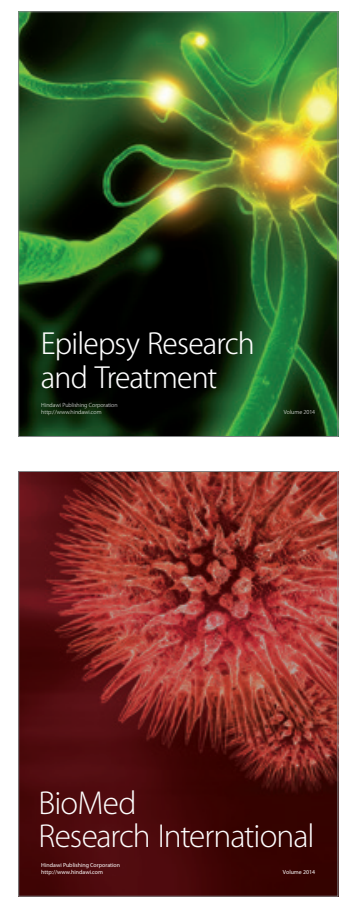

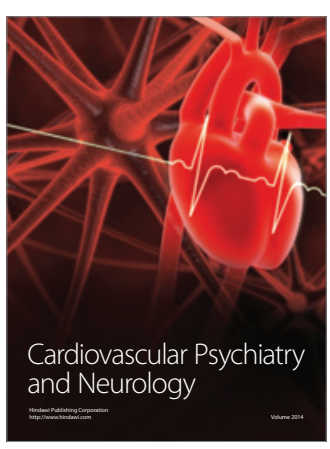

Parkinson's

Disease
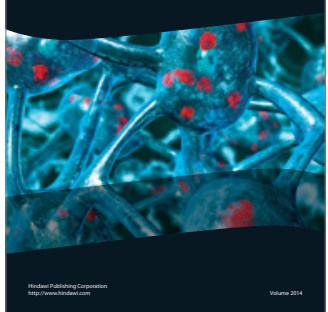